\title{
Prevalence of hypogonadism in young obese males
}

\author{
Authors: Anup Halappanavar ${ }^{A}$ and Rajeev Pakhetra ${ }^{B}$
}

\section{Background}

Ageing, obesity and chronic illness are major factors affecting serum testosterone $(\mathrm{T})$ levels in men. The magnitude of the impact of ageing on serum $\mathrm{T}$ levels is well established; for obesity this is less clear. ${ }^{1-4}$ Severe obesity may lead to isolated hypogonadotropic hypogonadism (IHH). Several explanations have been offered to clarify the presence of reduced T levels in obese men. One relates to the technique that is generally employed to measure serum androgen levels, ie measurement of total testosterone (TT) instead of free testosterone (FT). TT represents the sum of FT and T bound to albumin and sex hormone-binding globulin (SHBG). A profound reduction in SHBG level is commonly found in obese men, and this is a major factor causing a decrease in TT. ${ }^{4}$

Measurement of FT levels may provide a more accurate assessment of androgen status than the (usually preferred) measurement of TT in situations where SHBG levels are outside the reference range. However, reference ranges for FT levels are not well established, especially in older men, and some have argued that the measurement of FT levels merely reintroduces age in a covert form. ${ }^{5,6}$ This is a cross-sectional study to estimate prevalence of hypogonadism in young obese males.

\section{Methods}

The present study was carried out at Armed Forces Medical College and Command Hospital, Pune, India between October 2017 and August 2019. In this study 147 young obese men participated, and we confirmed low TT levels in $35.4 \%$ of participants with a p-value of 0.06 .

\section{Results}

We studied to see whether there is association between T levels and body mass index (BMI; Table 1). In our study we found no statistical association as the p-value was $0.26(>0.05)$.

\section{Discussion}

Since only TT was measured for categorising subjects with or without hypogonadism, FT measurement would be a better indicator for the diagnosis of hypogonadism in cases where the TT is borderline low or when SHBG concentrations are abnormal. As such, the study is valuable in the context of the ongoing controversy as to whether $\mathrm{T}$ treatment should be

Authors: ${ }^{\mathrm{A}}$ Armed Forces Medical College, Pune, India; ${ }^{\mathrm{B}}$ Command Hospital (SC), Pune, India

\begin{tabular}{|c|c|c|}
\hline Hypogonadism $(T<3$, LH $<9)$ & Number, $\mathrm{n}$ & Percentage, \% \\
\hline Present & 35 & 23.8 \\
\hline Absent & 112 & 76.2 \\
\hline Total & 147 & 100 \\
\hline
\end{tabular}

limited to men with classical hypogonadism, or be considered for appropriately selected men with functional hypogonadism as well. The principal findings are in general agreement with existing literature reporting correlation between levels of $\mathrm{T}$, $\mathrm{BMI}$ and constitutional symptoms. ${ }^{7-10}$ However, this has never been shown before in the context of the Indian population.

\section{Conflicts of interest}

None declared.

\section{References}

1 Tajar A, Forti G, O'Neill TW et al. Characteristics of secondary, primary, and compensated hypogonadism in aging men: evidence from the European Male Ageing Study. J Clin Endocrinol Metab 2010;95:1810-8.

2 Handelsman DJ. An old emperor finds new clothing: rejuvenation in our time. Asian J Androl 2011;13:125-9.

3 Bhasin S, Cunningham GR, Hayes FJ et al. Testosterone therapy in men with androgen deficiency syndromes: an Endocrine Society clinical practice guideline. J Clin Endocrinol Metab 2010;95:2536-59.

4 Dhindsa S, Miller MG, McWhirter CL et al. Testosterone concentrations in diabetic and nondiabetic obese men. Diabetes Care 2010;33:1186-92.

5 Glass AR, Swerdloff RS, Bray GA, Dahms WT, Atkinson RL. Low serum testosterone and sex-hormone-binding-globulin in massively obese men. J Clin Endocrinol Metab 1977;45:1211-9.

6 Allan CA, McLachlan RI. Androgens and obesity. Curr Opin Endocrinol Diabetes Obes 2010;17:224-32.

7 Orwoll ES, Nielson CM, Labrie F et al. Evidence for geographical and racial variation in serum sex steroid levels in older men. J Clin Endocrinol Metab 2010;95:E151-60.

8 Tan WS, Ng CJ, Khoo EM, Low WY, Tan HM. The triad of erectile dysfunction, testosterone deficiency syndrome and metabolic syndrome: findings from a multi-ethnic Asian men study (The Subang Men's Health Study). Aging Male 2011;14:231-6.

9 Sartorius G, Spasevska S, Idan A et al. Serum testosterone, dihydrotestosterone and estradiol concentrations in older men self-reporting very good health: the healthy man study. Clin Endocrinol 2012;77:755-63.

10 Isidori AM, Caprio M, Strollo F et al. Leptin and androgens in male obesity: evidence for leptin contribution to reduced androgen levels. J Clin Endocrinol Metab 1999;84:3673-80. 